Prepared for the U.S. Department of Energy under Contract DE-AC05-76RL01830

\title{
USE OF OPTICALLY STIMULATED LUMINESCENCE IMAGING PLATES AND READER FOR ARMS CONTROL APPLICATIONS
}

SD Miller

BJ Burghard

PL Tomeraasen RJ Traub

July 2001

\section{Pacific Northwest}




\title{
DISCLAIMER
}

This report was prepared as an account of work sponsored by an agency of the United States Government. Neither the United States Government nor any agency thereof, nor Battelle Memorial Institute, nor any of their employees, makes any warranty, express or implied, or assumes any legal liability or responsibility for the accuracy, completeness, or usefulness of any information, apparatus, product, or process disclosed, or represents that its use would not infringe privately owned rights. Reference herein to any specific commercial product, process, or service by trade name, trademark, manufacturer, or otherwise does not necessarily constitute or imply its endorsement, recommendation, or favoring by the United States Government or any agency thereof, or Battelle Memorial Institute. The views and opinions of authors expressed herein do not necessarily state or reflect those of the United States Government or any agency thereof.

\author{
PACIFIC NORTHWEST NATIONAL LABORATORY \\ operated by \\ BATTELLE \\ for the \\ UNITED STATES DEPARTMENT OF ENERGY \\ under Contract DE-AC05-76RL01830
}

Printed in the United States of America
Available to DOE and DOE contractors from the Office of Scientific and Technical Information,
P.O. Box 62, Oak Ridge, TN 37831-0062;
ph: (865) 576-8401
fax: $(865)$ 576-5728
email: reports@adonis.osti.gov

\begin{abstract}
Available to the public from the National Technical Information Service, U.S. Department of Commerce, 5285 Port Royal Rd., Springfield, VA 22161 ph: (800) 553-6847 fax: $(703) 605-6900$ email: orders@ntis.fedworld.gov online ordering: http://www.ntis.gov/ordering.htm
\end{abstract}

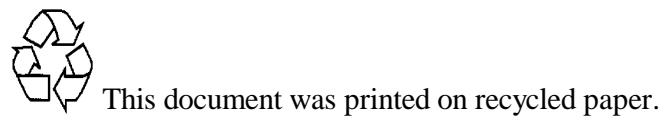




\section{Use of Optically Stimulated Luminescence Imaging Plates and Reader for Arms Control Applications}
SD Miller
BJ Burghard
PL Tomeraasen
RJ Traub

July 2001

Prepared for the U.S. Department of Energy under Contract DE-AC05-76RL01830

Pacific Northwest National Laboratory

Richland, Washington 99352 


\title{
USE OF OPTICALLY STIMULATED LUMINESCENCE IMAGING PLATES AND READER FOR ARMS CONTROL APPLICATIONS
}

\author{
Steve Miller, Paul Tomeraasen, Brion Burghard, and Rick Traub \\ Pacific Northwest National Laboratory (PNNL) \\ P.O. Box 999 Richland, WA 99352 USA 509/375-2843
}

\begin{abstract}
Optically Stimulated Luminescence (OSL) technology has been pioneered at the Pacific Northwest National Laboratory (PNNL) for applications in personnel radiation dosimetry and has become highly successful commercially in replacing older technologies such as Thermoluminescence Dosimeters (TLDs) and film. OSL phosphors are used to measure ionizing radiation exposure by illuminating the phosphor with light and measuring the amount of light emitted. The light emitted by the OSL phosphor is directly proportional to the radiation exposure received. By using a twodimensional plate of OSL material and raster scanning a light beam across the OSL plate a radiation pattern or image can be measured.
\end{abstract}

The Arms Control community may find it desirable to use an electronics-free medium to measure certain attributes, such as the extent and symmetry of Pu pits in storage containers. OSL technology, used in the two-dimensional imaging mode, provides a means to measure these attributes with exposure times on the order of an hour. A special OSL reader has been built by PNNL to measure OSL imaging plates with a size of $20 \mathrm{~cm}$ by $30 \mathrm{~cm}$. The reader uses 10 light emitting diode clusters with 10 corresponding photomultiplier tubes to measure an OSL imaging plate in less than 5 minutes. The resolution of each of the 10 measurement assemblies is 1 square-centimeter. An collimator assembly employing a Venetian-blind type collimator is used in conjunction with the OSL film to image the Pu pit within the storage container. The output of the OSL reader is a two-dimensional array of intensities that will be used with the appropriate information barriers to measure extent and symmetry. This device also clearly distinguishes the difference between a point source and a distributed source. Details of the OSL technology, OSL reader system, collimator design, and system performance will be presented.

\section{INTRODUCTION}

The Pacific Northwest National Laboratory (PNNL) has been a pioneer in the development of a new radiation detection technique known as Optically Stimulated Luminescence (OSL) for personnel dosimetry. The OSL technique is a patented and patent pending technology that relies on specially formulated crystalline phosphors that store the effects of radiation exposure. The OSL phosphors are uniquely able to store the radiation exposure information in the form of an image and then later, when subjected to light exposure, the image is rendered visible through the use of specialized readout equipment. The OSL phosphor image plate most closely resembles the X-ray film used in the medical and dental professions in form and function. Both image media take the form of a flat sheet. The method of storing and developing the radiation images set the two techniques apart. OSL phosphor materials do not require chemical processing as does X-ray film and therefore are more environmentally friendly. In addition to this important difference, the OSL image plates enable a more efficient conversion to digital form (a computer readable form), are reusable, and are much more tolerant of higher radiation exposures compared to X-ray film. OSL technology has a dynamic 
range of 8 orders-of-magnitude versus only 3 for X-ray film. X-ray film can easily be overexposed with large radiation exposures destroying the image whereas the OSL image plate continues to be useful even at large exposures.

The OSL technology has certain advantages over conventional X-ray film radiography in the Arms Control community. The readout of the image can be made in a low-resolution form that will not reveal critical dimensions important to nuclear weapon design. The low-resolution characteristic is achieved in the design of the image plate readout system.

The readout instrument that applies light to the image plate for the purposes of developing the stored radiation image into a visible form (see Figures 1 and 2) can also be tailored to produce a low-resolution image. The image plates are read out in discrete panels; light from 10 clusters of light-emitting diodes (LEDs) is applied to 10 small panels of the image plate for a brief moment while the radiation exposure information is collected. This process is repeated until the entire plate is readout. PNNL's engineers have devised a clever configuration that steps through the image plate and completes the readout in the shortest possible time (5-10 minutes per image plate). By controlling the size of the light beam the dimensions of the panel become the limiting resolution dimension. One square-centimeter was chosen as the panel size and therefore the OSL image plates will not be able to resolve an image feature smaller than one centimeter.

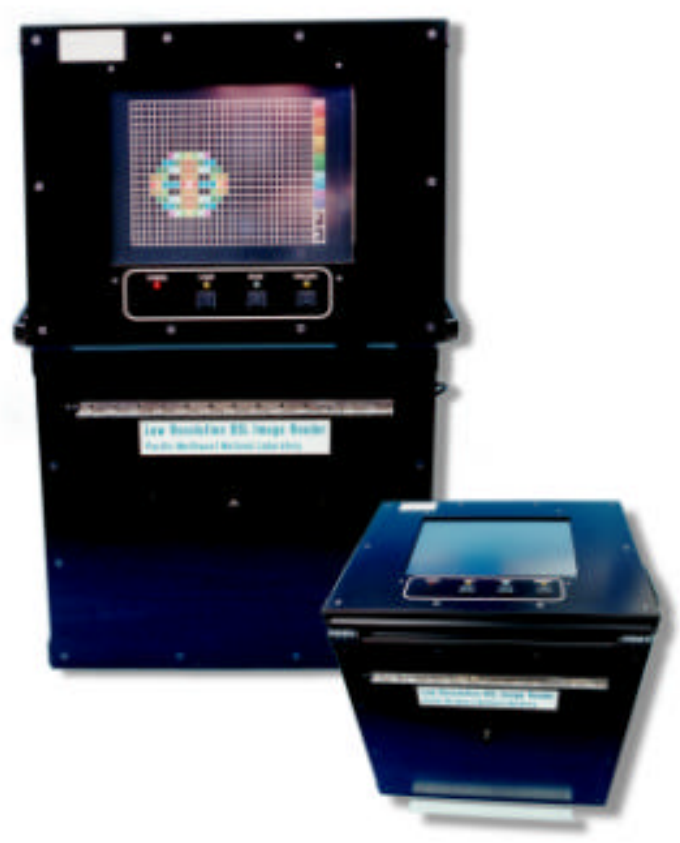

Figure 1, Reader - front view

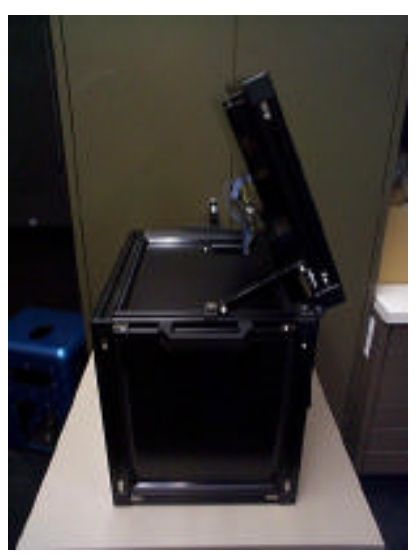

Figure 2, Reader - side view

\section{TESTING OF COMMERCIAL HIGH-Z OSL PLATES}

The PNNL OSL phosphor was developed for personnel dosimetry applications where human tissue equivalence is important. To achieve tissue-like dosimetry one must choose very low atomic 
number or low " $Z$ " materials. While this choice is highly beneficial to the dosimetry community it does not optimize the sensitivity for arms control applications. A search for commercially available higher " $Z$ " OSL phosphors found that Kodak has a very high " $Z$ " OSL plate available in an 8" by 10" size. The Kodak OSL plate is based on BaFBr:Eu and is used commercially as a replacement for X-ray film in some applications. The higher " $Z$ " properties of the Kodak film were believed to offer much higher sensitivities than the PNNL developed phosphor due to the greatly increased Xray absorption of the Kodak plate. Kodak was contacted and they were able to provide us with some 8 " by 10" films for testing. Using small pieces of the Kodak OSL film we were able to measure a ten-fold increase in sensitivity over our PNNL OSL film at X-ray energies. This encouraged us to modify the OSL image plate reader so that it could measure the Kodak plates.

When the Kodak films arrived they had a black coating on one side of the film that required removal with an acetone/alcohol mixture. In order to read the Kodak OSL plates, changes had to be made to the filtering and light sources currently used in the image plate reader. The Kodak phosphor requires a yellow light source for excitation compared to a green light source for the PNNL phosphor. Fortunately the same company that manufactured our green LED modules also had similar LED modules available in yellow. A dozen were ordered and installed in the reader. The optical filters used to pass green light also had to be changed to accommodate the change in wavelength. When the OSL reader was reassembled it was found that the new OSL sheets were in fact much more sensitive. We achieved around a factor of ten increase in sensitivity.

Due to the increased sensitivity it was determined that we could reduce the readout time per pixel from 5 seconds to 2 seconds. This change reduced the readout time for an entire 8" by 10 " sheet to just over 2 minutes.

\section{MODELING AND DEVELOPMENT OF A COLLIMATOR FOR IMAGING WEAPONS COMPONENTS}

\section{Differentiation of Point and Distributed Radiation Sources}

The ability to distinguish between a point and distributed source of radiation that is contained in a metal drum or other container is important to non-intrusive inspection of weapons components. If the drum cannot be opened for inspection, imaging techniques can be used to help distinguish between the two types of source configuration.

\section{Calculations}

Energy deposition calculations were performed using MCNP Version 4B for two dissimilar types of radiation sources, a discrete point source and a distributed spherical source, and two collimator configurations. The energy deposited in the phosphor material is directly proportional to the magnitude of the readout.

The source container was modeled as a steel drum $69 \mathrm{~cm}$ high, having a radius of $23 \mathrm{~cm}$. The walls of the drum were $0.13 \mathrm{~cm}$ thick. The elemental composition of the drum was iron having a density of $7.86 \mathrm{~g} / \mathrm{cm}^{3}$. The drum was lined with $7.62 \mathrm{~cm}(3 \mathrm{inch})$ thick cellotex, which was modeled as carbon having a density of $0.3 \mathrm{~g} / \mathrm{cm}^{3}$. 
Two sources were modeled; a point source and a distributed source. The point source was modeled as a discrete point in the center of the steel drum. The distributed source was modeled as a sphere centered in the drum. The sphere was composed of plutonium having a density of $19.86 \mathrm{~g} / \mathrm{cm}^{3}$.

The collimator was modeled as $0.3175 \mathrm{~cm}$ thick ( $1 / 8$ inch) fins that were perpendicular to the vertical axis of the steel drum. The inner radius of the fins was $0.01 \mathrm{~cm}$ from the outer radius of the steel drum. The collimator fins were modeled as either 2.5 or $4.0 \mathrm{~cm}^{\mathrm{s}}$ long. The collimator fins had a $1 \mathrm{~cm}$, center-to-center, spacing over a 20-cm distance. The collimators extended $10 \mathrm{~cm}$ above and below the center of the steel drum. The collimator was modeled as white tin having a density of $7.31 \mathrm{~g} / \mathrm{cm}^{3}$. The detector was modeled as an alumina/polyethylene film, $20 \mathrm{~cm}$ wide and $0.0762 \mathrm{~cm}$ (30 mil) thick. The density of the detector film material was $1.22 \mathrm{~g} / \mathrm{cm}^{3}$.

\section{Results}

The results of the calculations are shown in the following figures. The difference between the figures is that for figures 3 and 5, the energy deposition in the film interval has been normalized to the average energy deposition over the whole detector film. For Figures 4 and.6, the energy deposition has been normalized to the minimum energy deposition in the collimator intervals.

The figures show that it is possible to differentiate between point and spherical sources using alumina/polyethylene film as a detector when the radiation is collimated with tin sheets. The figures also show that the $4.0 \mathrm{~cm}$ long collimator is better than the $2.5 \mathrm{~cm}$ long collimator in two respects. First, the peak of the point source is narrower with the longer collimator. Second, the difference between the lowest and highest energy deposition for the $4.0 \mathrm{~cm}$ collimator is twice that of the 2.5 cm collimator.

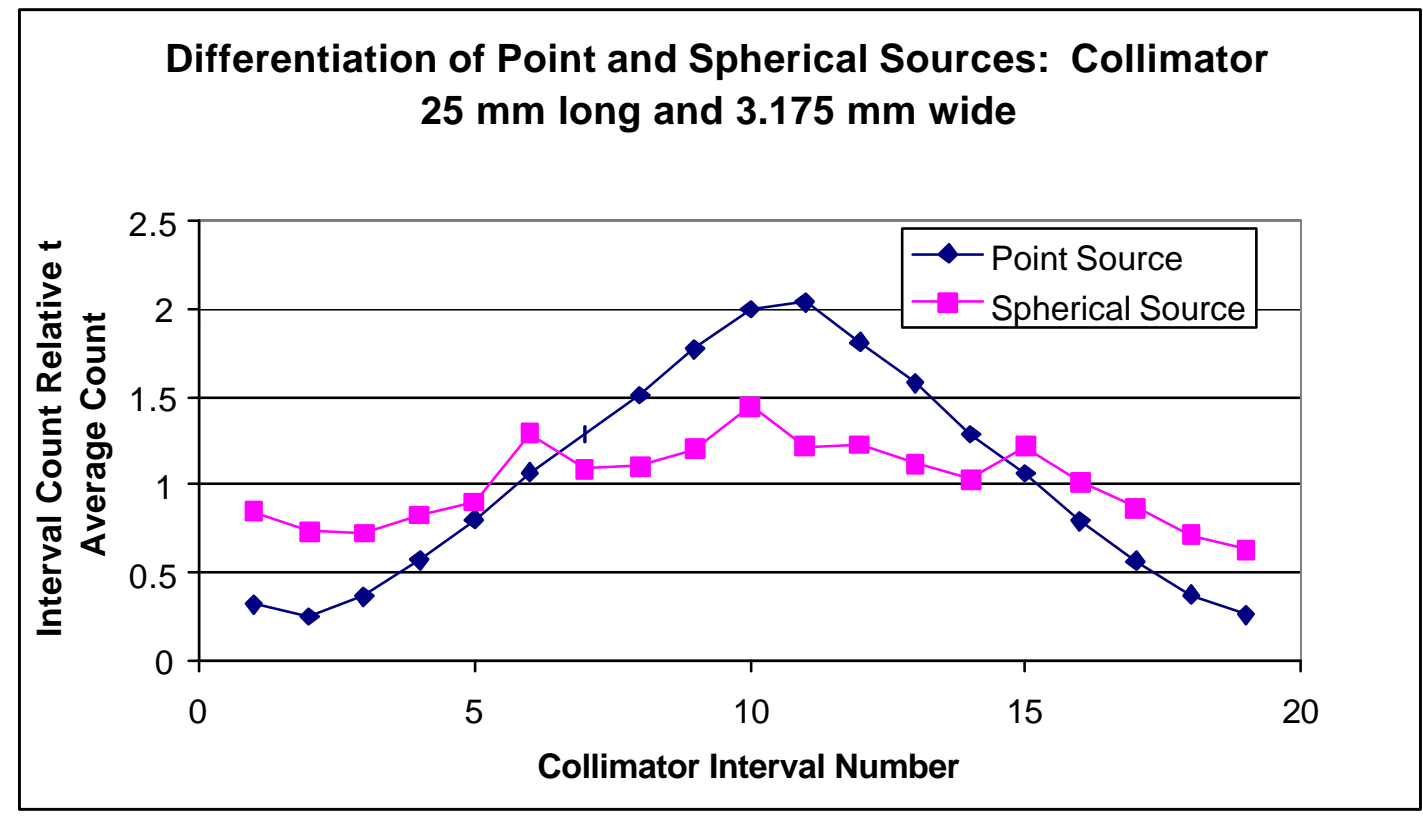

Figure 3, $25 \mathrm{~mm}$ collimator, energy deposition normalized to average 


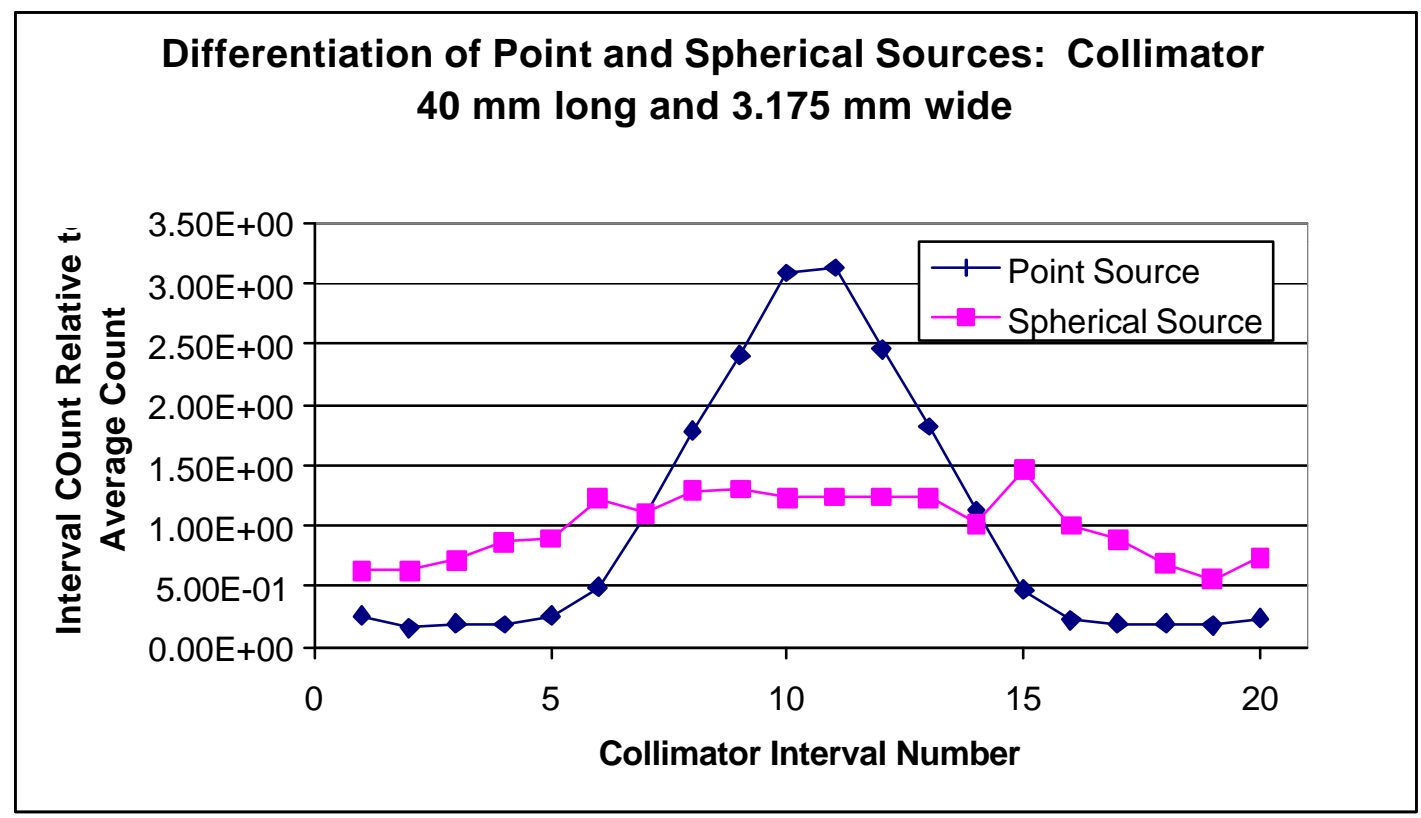

Figure 4, $25 \mathrm{~mm}$ collimator, energy deposition normalized to minimum

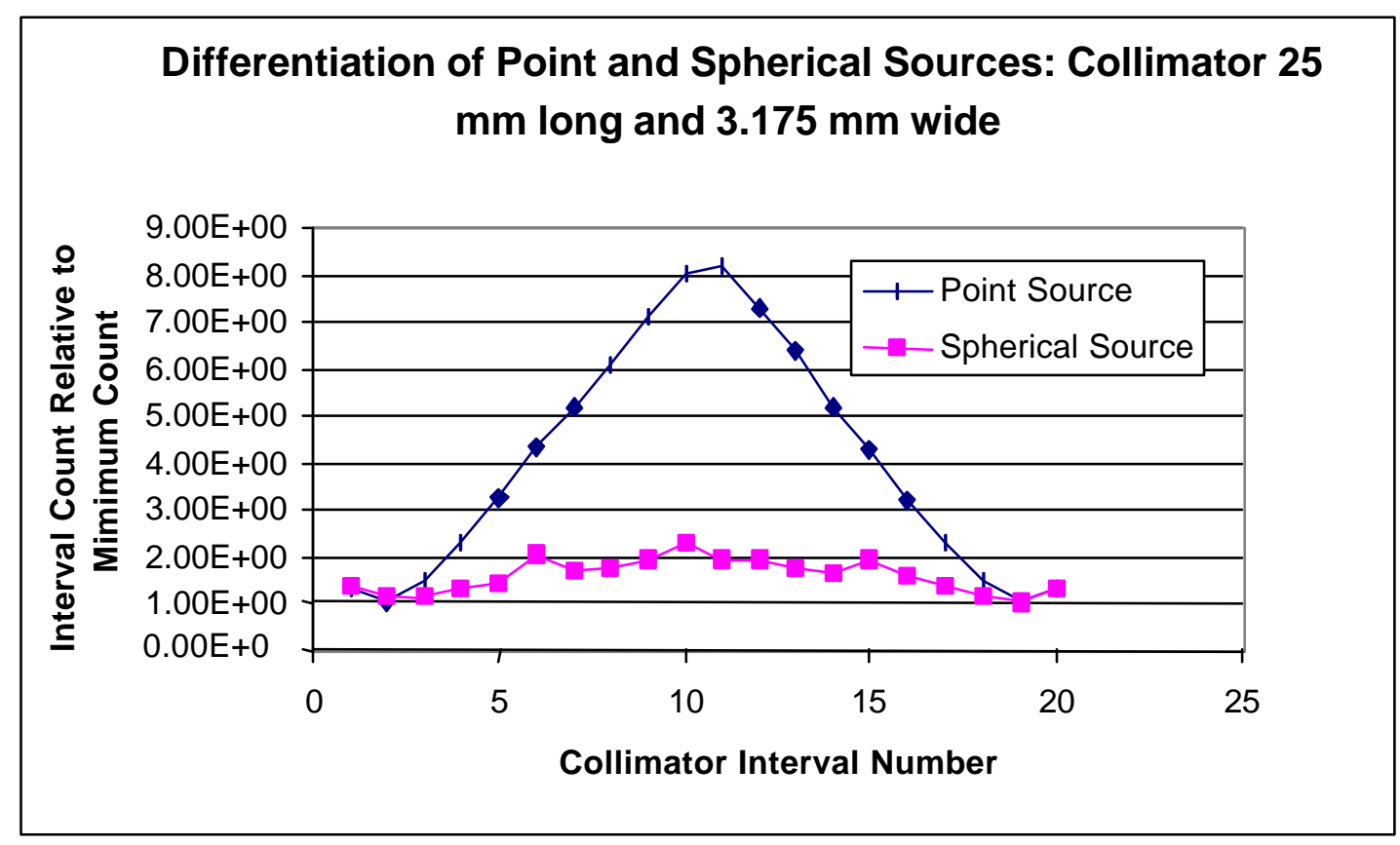

Figure 5, $40 \mathrm{~mm}$ collimator, energy deposition normalized to average 


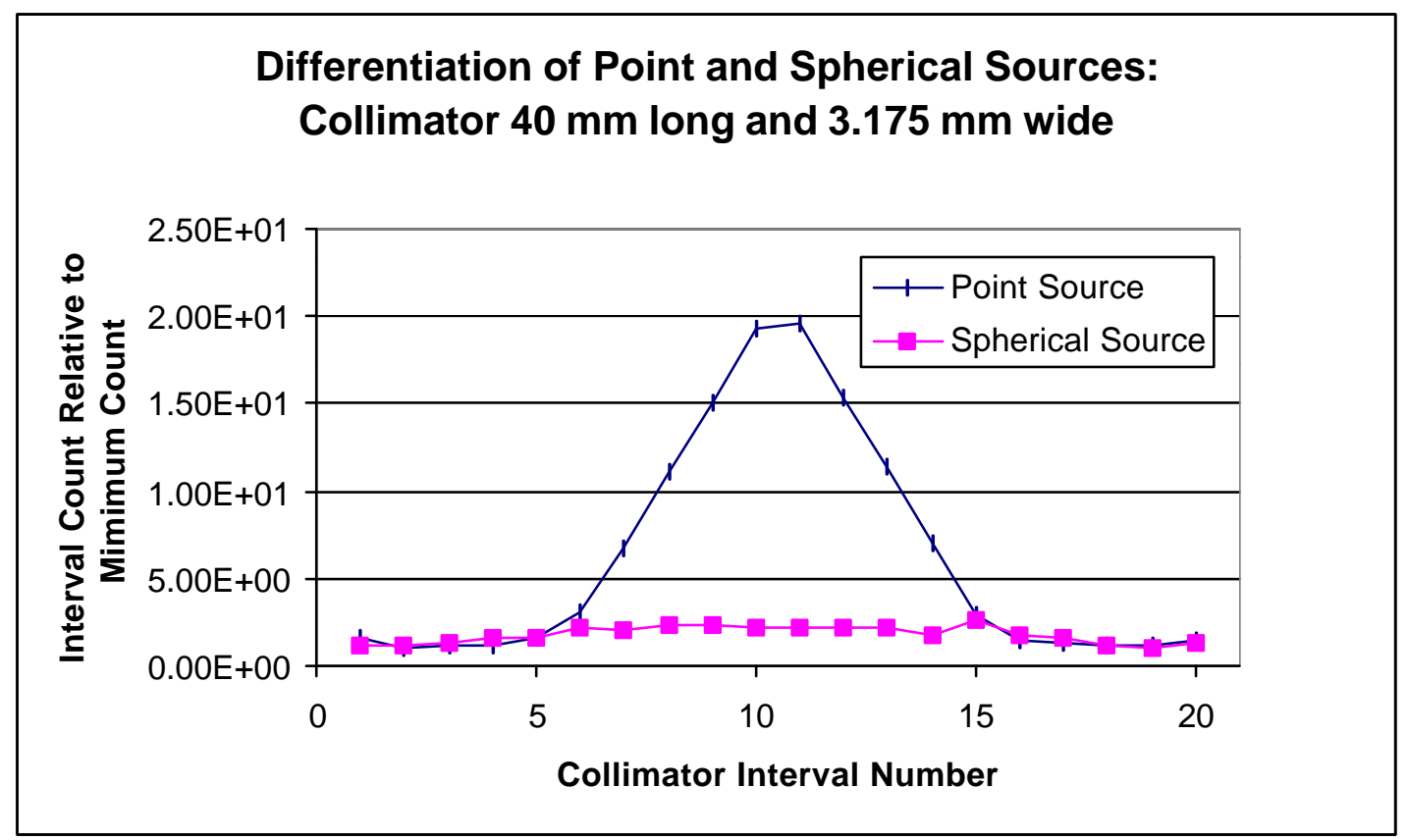

Figure 6, $40 \mathrm{~mm}$ collimator, energy deposition normalized to minimum

As can be seen from the calculations the longer collimators produced much better discrimination between a spherically-distributed source and a point source. Based on these results it was decided to build collimators of the longer dimension. PNNL mechanical design engineers were tasked to come up with a design that was mostly plastic (besides the tin collimator slabs) and easy to construct and position the collimator/OSL film package. The all-plastic design was suggested by Wayne Kiehl (DOE Pantex Plant, Amarillo, TX) in order to pass safety requirements to work around High Explosives. A picture of the collimator assembly can be seen in Figure 7. 


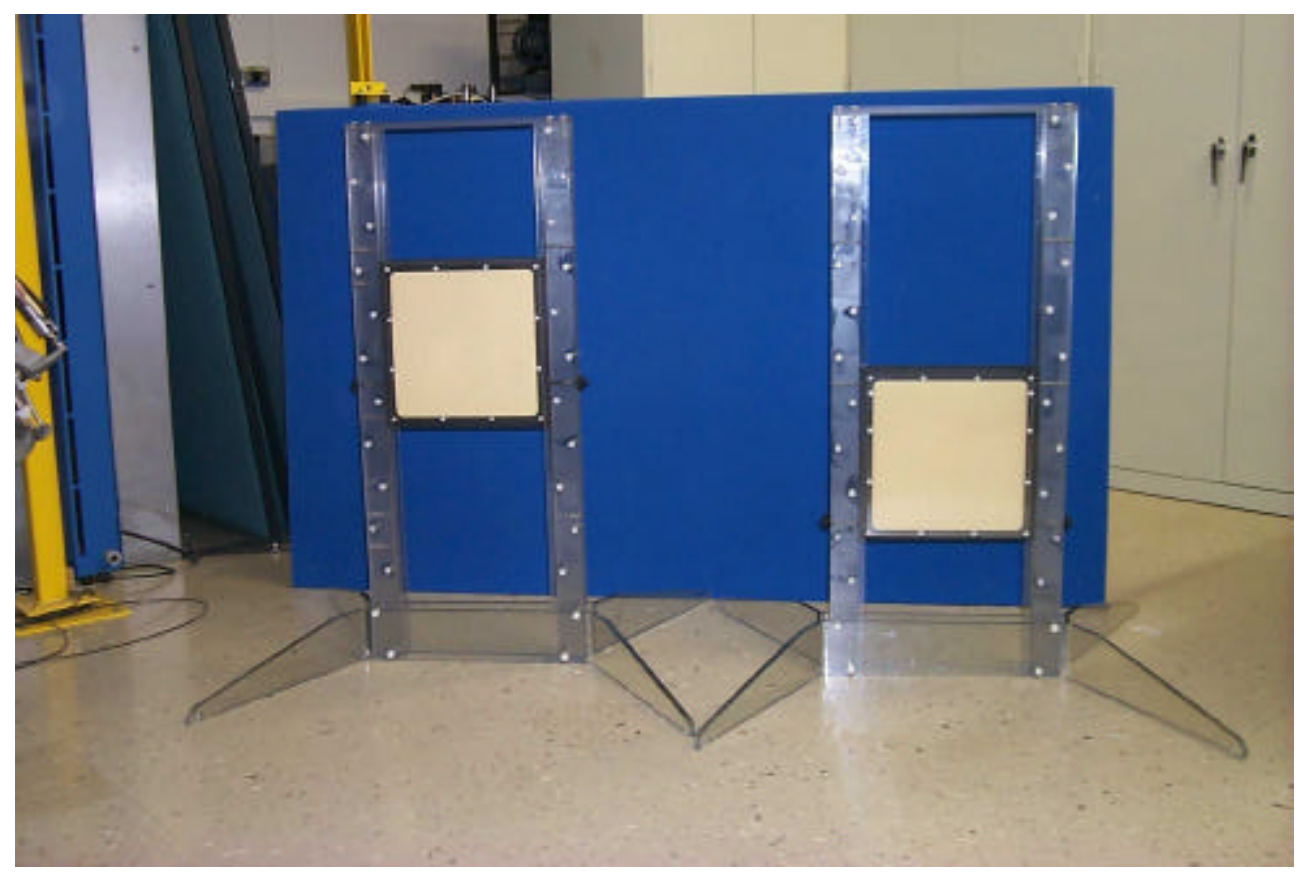

Figure 7, PNNL designed and built collimators

The legs of the collimator assembly were designed to position the collimator adjacent to an AL-R8 pit storage container and provide stability to prevent the collimator assembly from tipping over. Height-adjusting holes were drilled every two inches to permit vertical adjustment of the collimator. A finger-adjustable screw can be inserted into the collimator when the desired height has been reached and then tightened to maintain the correct positioning. The tin collimators are a twodimensional Venetian blind-type collimator with $1 \mathrm{~cm}$ center-to-center spacing. The collimator was made square to enable the device to be rotated 90 degrees in order to be able to make measurements in either the horizontal or vertical orientation. When the AL-R8 containers are in the six-pack storage configuration it is anticipated that the OSL measurements can be taken with these collimator assemblies by centering the collimator assembly on the lids of the containers. 


\section{SAMPLE IMAGE TAKEN WITH THE PNNL LOW-RESULTION OSL READER}

Figure 8 is an exposure of an OSL image plate using low energy $60 \mathrm{keV}$ X-rays with a lead annulus. The OSL film was placed into a light-tight black plastic bag and the lead annulus was placed on contact with the film. The "contact print" was exposed and then readout using the PNNL lowresolution OSL reader. As can be seen from the image the areas shielded by the lead had a low OSL output and unshielded areas produced very high counts. The black pixels correspond to the lowest levels of OSL signal, whereas the OSL signal increases from dark blues to greens to the highest signals represented by the red and pink pixels.

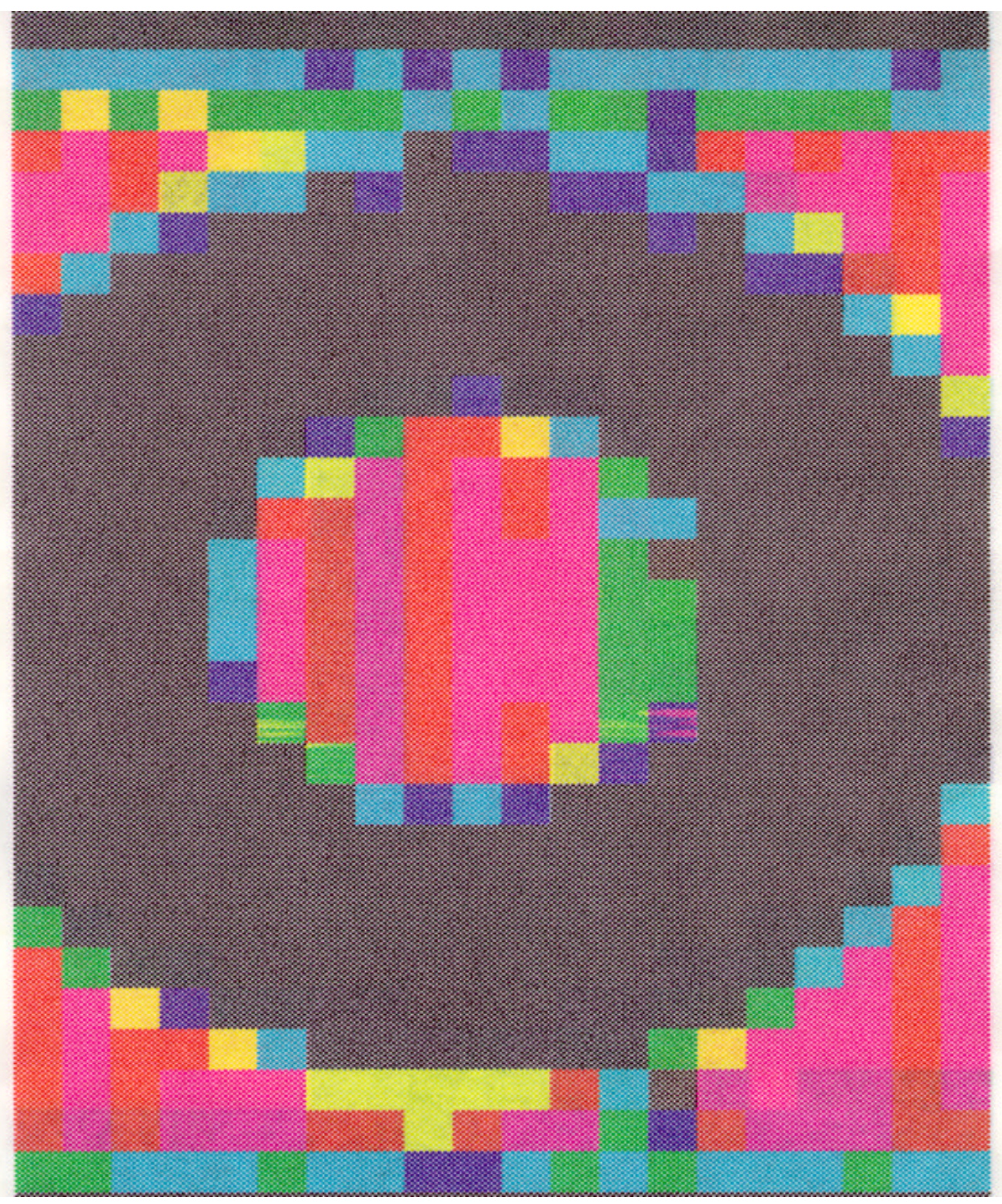


Figure 8, OSL image plate readout of an X-ray annulus exposure

\section{SUMMARY}

The PNNL developed low-resolution imaging reader is a mature technology that is currently being tested for applications in nuclear arms control. Initial testing of the system has been completed at Pantex and further testing is being planned. The reader, in conjunction with the Venetian-blind collimators, provides a tool that is capable of distinguishing between a point source and a distributed source. Further, the OSL system may be capable of measuring the attributes of extent and symmetry, within the resolution dictated by the OSL reader system. The OSL system does all of this with a simple electronics-free medium that may potentially be used in arms control applications.

\section{ACKNOWLEDGEMENT}

This work was performed by the Pacific Northwest National Laboratory, which is operated for the U.S. Department of Energy by Battelle Memorial Institute under Contract DE-AC06-76RLO-1830. The authors would like to acknowledge the past support of the U.S. Department of Energy and the current support of the Defense Threat Reduction Agency's Arms Control Technology Division for this work, which is part of the Joint DOE/DoD Integrated Technology Implementation Plan. 